\title{
POTENTIAL FISH GROUND BREEDING AREA BASED ON LOCALIZED CRITERIA FOR SUSTAINABLE FOOD SECURITY
}

\author{
Nor Ainn Alfatihah Zamzuri, Muhammad Imzan Hassan \\ Faculty of Built Environment \& Surveying \\ Universiti Teknologi Malaysia \\ ainnalfatihah@gmail.com,imzan@utm.my
}

KEY WORDS : Fisheries, Artificial Reefs, Ground Breeding Area, Parameters, Criteria, Localize, MCDA, Weighted Analysis

\begin{abstract}
:
Fish are the part of marine ecosystem and play an important role as contributors of nutrients and dependent on the ecosystem which is affected by the parameters to provide the right conditions for reproduction. Artificial reefs were being applied as an approach to sustain food security. Food security is a major concern for all countries in the face of population increase and diminishing water supplies including in the fisheries sector. Hence, artificial reefs become one of the methods to improve the preservation of fish supplies. Suitable environment for fish ground breeding area need to be identified in order to place the artificial reef. Therefore, this study is proposed to locate the potential fish ground breeding area in Terengganu, Malaysia based on localized criteria which is suitable to place the artificial reefs by examining the parameters in the area. Parameters that have been studied were water temperature, water salinity, water acidity, chlorophyll concentration and dissolve oxygen. Those parameters have their own criteria that represent the suitability for fish population. Localized data have been applied in order to analyse and support localized criteria for this study area. To locate the potential fish ground breeding area, Geographic Information System (GIS), Multi-criteria Decision Analysis (MCDA), Spatial Interpolation and Weighted Analysis have been applied. For MCDA, Analytical Hierarchy Process (AHP) has been used to get the weightage of the parameters by running Pairwise Comparisons between the selected parameters using AHP software, Expert Choice. Then, those parameters weightage were applied in weighted analysis to identify the potential ground breeding area. At the end of this study, final map showing the location for fish ground breeding area. The final output resulted potential location for fish ground breeding area in four classes which are very high, high, medium and low potential area. This study may facilitate the decision makers to place the artificial reefs in potential area to increase fish population.
\end{abstract}

\section{INTRODUCTION}

Fish are the part of marine ecosystem and play an important role as contributors of nutrients to marine ecosystem. This aquatic life interacts closely with their physical, chemical and biological environment. Parameters in the ecosystem provide the right conditions for growth, reproduction and survival of the aquatic life. Parameter is defined as independent variable used to express the coordinates of a variable point and functions of them. The examples of parameters are water clarity, water temperature, turbidity water, salinity water, type of sediment in that area and etc. Those parameters have their own criteria that represent the suitability for fish population. The criteria of parameters will determine the area weather it is suitable for fish ground breeding area or not. Fish ground breeding area can be assumed as the area that suitable for fish spawning and maturing plus this area tends for fish distribution (Barletta et al., 2005).

Fish population plays an important part because fisheries and aquaculture aid the livelihoods of almost half a billion humans internationally. However, the world's fisheries are at grave risk from human pressure including over exploitation, pollution and habitat change (Fathi et al., 2018). Fish stocks had been decrease with the aid of overfishing, illegal and damaging fishing practices and susceptible fisheries management. This has led lack of fish stocks to meet high demand in line with economic growth. In order to overcome the problem, artificial reefs were being applied as an approach to sustain food security. Food security is a major concern for all countries in the face of population increase and diminishing water supplies including in the fisheries sector. Hence, artificial reefs become one of the methods to improve the preservation of fish supplies. Suitable environment for fish ground breeding area need to be identified in order to place the artificial reef. It is important to know the appropriate environment to place the artificial reefs to lead the fish population. As mentioned earlier, the ecosystem for fish is affected by parameters involved in that area. Therefore, the criteria for the parameters need to be identified whether the ecosystem in a particular area is suitable for fish ground breeding area.

This research is proposed to study the criteria of defined parameters involved and to identify their criteria for fish population. Localized data have been applied in order to analyse and support localized criteria for this study area. Standard of criteria that has been established may not be suitable for this study area because of different environments and different monsoon. For instance, the optimum water temperature for mackerel $\left(7^{\circ} \mathrm{C}\right)$ in Atlantic Ocean is different to the water temperature for mackerel in South China Sea $\left(>17^{\circ} \mathrm{C}\right)$. Hence, localized data is being used to make sure the criteria standard for the parameter's criteria is correct and align with localized area. The data of each parameter collected in Terengganu Coastal Area (Figure 1) and will be analyzed to know their criteria. The scopes of the study area cover the following:

(a) Research Area

- The research area is covered Terengganu East Coastal only.

- Research area for this study is around $2895 \mathrm{~km}^{2}$ with the distance between the stations are around 4 to $12 \mathrm{~km}$. 


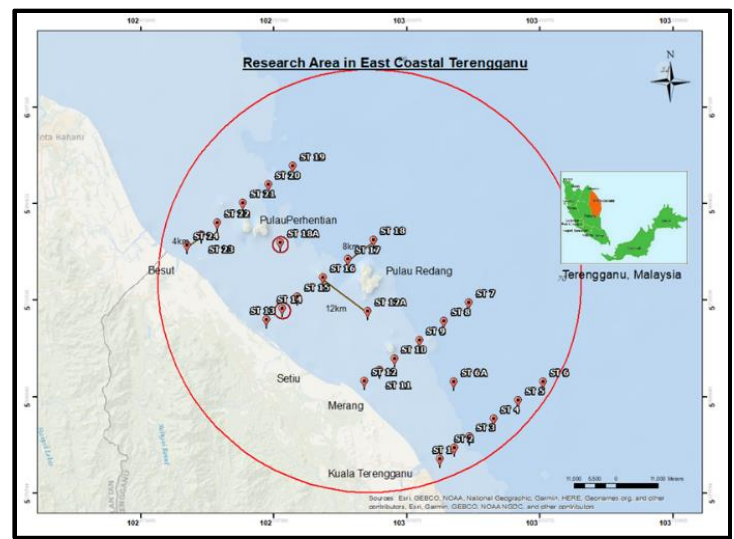

Figure 1. Study Area, Terengganu East Coastal

(b) Data or Samples

- 27 samples of parameters collected in the research area.

- Element temporal become as limitation in this study because of data availability.

The data were collected at several locations in the study area. Therefore, spatial interpolation method is being used to estimate the value of unknown value at the other area based on known value. Then, the parameters will be going through Multiplecriteria Decision Analysis (MCDA). MCDA is a sub-discipline of operations research that explicitly evaluates multiple conflicting criteria in decision-making and it becomes as platform to obtain parameters' weight. The parameters weightage will be used in weighted overlay analysis to identify the potential fish ground breeding area. This study has been summarized by the Figure 2 below.

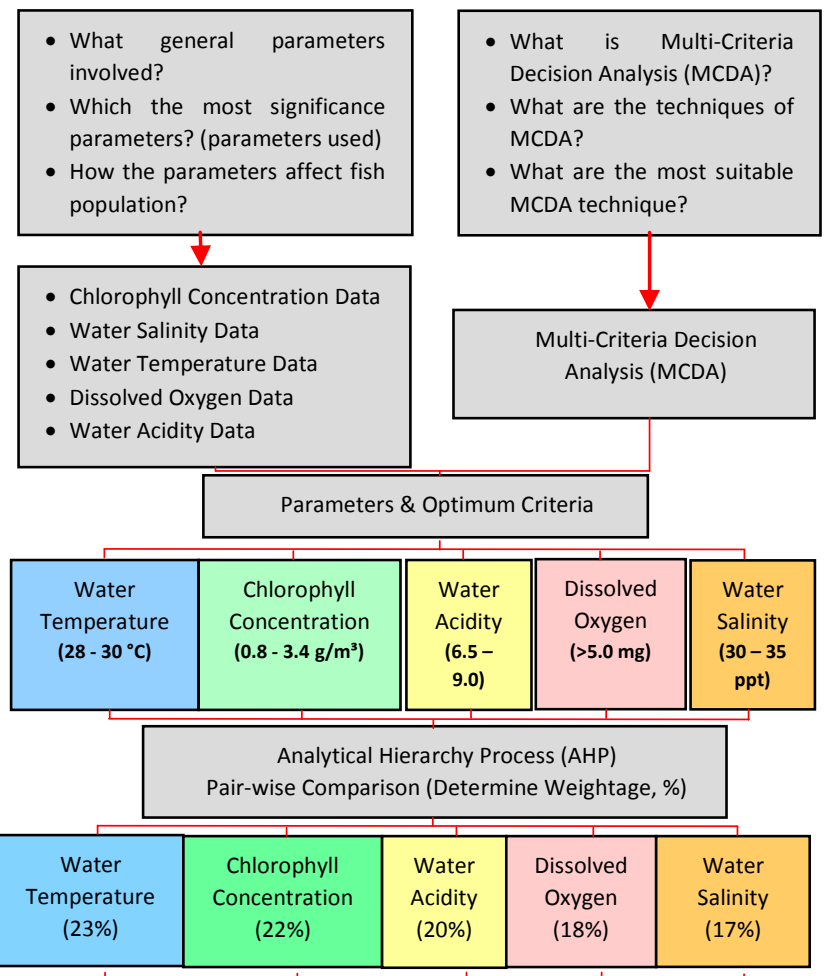

Figure 2.

Weighted Overlay (Overlay the data)

Visualize potential map

Flow chart

\subsection{Fisheries}

Fishes are the first food supply of the native inhabitants, with some areas showing the best consumption rates within the world. However, fish source has been decrease due to a few factors such as issues of fish stock depletion, climate changes, current diseases, media influences in the sector, non-compliance feeding practiced and poor interaction between stakeholders. Besides, the dynamics of fish stocks could alter because of environmental changes (Barletta et al., 2005), overfishing, global climate change, pollution, deforestation, etc. Growth parameters of fishes are the key indicators that may alter the assessment of the impact of such processes on fish populations. Currently, global fish stock decline caused by large exploitation and ineffective fisheries management (Fathi et al., 2018). In Asian country, pollution, climate change and foreign vessels encroachment into Malaysia water as well as prohibited zones intruded by native fishing vessels have resulted in national wild fish catch depletion besides overfished resources. Since the capture fisheries production decreasing whereas fishing operations value raising, the fish price could increase along the rapid growth of aquaculture.

Many approaches have been done to increase the number of fish capture. One of the approaches is fish capture technology. Fish capture technology has been developed to become as electronic instruments and fish detection equipment that is can lead to more rapid location of the fish. Fish capture technology encompasses the method of catching any aquatic animal, mistreatment any quite fishing ways, usually operated from a vessel. Use of fishing ways varies, looking on the categories of fisheries, and might vary from an easy and little hook connected to a line to giant and complex mid-water trawls or purse seines operated by giant fishing vessels. The targets of capture fisheries will embrace aquatic organisms from small to big invertebrates. Another approach is housing artificial reefs at the location or area that has suitable environments for the fish spawning and maturing. In other word, artificial reefs have been placed to create a new habitat for fish ground breeding area.

\subsection{Artificial Reefs}

Artificial reefs in Malaysia provide a number of intended uses. To establish the artificial reefs area, various types of materials and mechanism have been used. In Malaysia, these structures had been placed in both non-protected and protected marine areas. Deployment of artificial reefs is seen as a fast resolution to mainly the problems of declining fish stocks, natural reef degradation associated a sweetening of the dive touristy trade. These structures alter the discourse of a natural marine environment and this might adversely affect the marine life. The establishment of artificial reefs has influenced the surrounding underwater ecosystem because a new habitat can be created which potentially might help the abundance and distribution of living resources (Bohnsack \& Sutherland, 1985).

New spawning sites can be established by housing the artificial structures (Sheehy \& Vik, 2010). Artificial reefs are often popular destinations for divers, snorkelers and fishermen because they able to create habitats for a variety of marine life. Therefore, their creation can also alter human use by shifting recreational diving and fishing patterns (Leeworthy et al., 2006). Artificial reefs can be established by using various types of materials. The materials and design of artificial reefs affect their relative value as a fisheries enhancement tool. Most artificial reefs consisted of manufactured materials, such as metal or concrete. The increasing structural volume and 
complexity of artificial reefs and higher species abundance with larger, more structurally complex reefs like structures with holes, overhangs, and shadows providing more opportunity for animals to recruit and thus may lead to a higher local biological diversity. Table 1 shows the variety of materials type with their benefits.

Table 1. Types of artificial reefs

\begin{tabular}{|c|c|}
\hline $\begin{array}{c}\text { Material } \\
\text { Type }\end{array}$ & Benefits \\
\hline Concrete & $\begin{array}{l}\text { - Cost effective and readily available } \\
\text { - Material is compatible with marine } \\
\text { environment. } \\
\text { - Provides surfaces for settlement and growth }\end{array}$ \\
\hline $\begin{array}{l}\text { Steel } \\
\text { Hulled } \\
\text { Vessels }\end{array}$ & $\begin{array}{l}\text { - Make for interesting diving locations } \\
\text { - Durable at certain depth. } \\
\text { - Attract both pelagic and demersal fishes. } \\
\text { - Provide surface area for epibenthic } \\
\text { colonization. }\end{array}$ \\
\hline $\begin{array}{l}\text { Oil and } \\
\text { Gas } \\
\text { Platforms }\end{array}$ & $\begin{array}{l}\text { - Provide habitat for a variety of species } \\
\text { - Durable and stable. } \\
\text { - Readily available. }\end{array}$ \\
\hline Tires & $\begin{array}{l}\text { - Easy to handle and readily available. } \\
\text { - Low cost and long lifespan. }\end{array}$ \\
\hline
\end{tabular}

These artificial reefs need to be placed in suitable environment in order to make sure the fish can live healthily. Thus, parameters their criteria in the area need to be identified weather the area is suitable to place the artificial reefs or not.

\section{PARAMETERS \& CRITERIA}

For this study, the parameters have been studied. The criteria for the parameters are defined by studying the previous research and supported by localized data. In previous research, those criteria were compared with standard of parameters' criteria for fish environment that has been established. Localized data are the data of parameters collected within the study area boundary. This data collected in the area that has many of fish numbers which are contained the optimum criteria for fish distribution. Thus, the optimum criteria for the parameters were supported by localized data. The parameters that have been used in this study were water temperature, chlorophyll concentration, water acidity, dissolved oxygen and water salinity.

\subsection{Water Temperature}

Water temperature is a standout amongst the most critical physical variables influencing fish population. Productivity will be influenced by the effect of temperature on growth rate (Teal et al., 2008). Fish are cold-blooded animals that proximately assume the same temperature as their surroundings. Typically, fish are labelled broadly as cold, cool or warm water, leaning on their tolerance for particular temperature ranges. Temperature is a predominant factor determining habitat selection, also guiding daily and seasonal movements in many fish species (Crawshaw \& Podrabsky, 2011). Within each temperature classification, fish survival is constrained by an upper and lower temperature, between which an optimum temperature for growth exists. Water temperature can also prevail against the solubility of gases that are important to fish health such as dissolved oxygen and ammonia nitrogen. In general, the solubility of gases decreases once water temperature increases. An increase in juvenile growth as well as an increase in temperature may result in a decrease in the length and age at first maturation, affecting the growth of adults as surplus energy is channelled into reproduction at an earlier age and smaller size (Heino \& Godoe, 2002). Table 2 shows the class of criteria and their ranking for water temperature.

Table 2. Criteria and Ranking for Water Temperature (Source : Siddiquee et al., 2011)

\begin{tabular}{|c|c|c|}
\hline Temperature $\left({ }^{\circ} \mathbf{C}\right.$ ) & Range & Ranking \\
\hline $17-24$ & Range for microalgae & 4 \\
\hline $25-27$ & Suitable range & 2 \\
\hline $28-30$ & Optimum range & 1 \\
\hline $31-34$ & Moderate Range & 3 \\
\hline$>35$ & $\begin{array}{c}\text { Lethal for number of } \\
\text { species }\end{array}$ & 5 \\
\hline
\end{tabular}

The best range value for water temperature is the optimum range $\left(28-30^{\circ} \mathrm{C}\right)$. This optimum range is most suitable criteria for fish spawning and maturing. The ranking for water temperature criteria shown in the Table 2. The first ranking means most suitable criteria for fish ground breeding area.

\subsection{Chlorophyll Concentration}

Chlorophyll is a green pigment, present in all green plants and in cyanobacteria, responsible for the absorption of light to provide energy for photosynthesis. The concentration of chlorophyll is an indicator for the amount of photosynthetic plankton, or phytoplankton, present in the ocean. Phytoplankton populations are influenced by climatic factors such as sea surface temperatures and winds. Cold water generally has higher chlorophyll concentrations than warm water because it contains nutrients that have recently come up from the deep ocean. The visualization of satellite images is the primary technique used to identify their presence, in particular when phytoplankton blooms occur as a regular event in a specific ocean region. Satellites measure the colour of the ocean as an indication of the amount of chlorophyll present. In the absence of chlorophyll, water appears blue.

Chlorophyll has a green pigment, which means that it absorbs red and blue light and reflects green light. Chlorophyll concentration provides a measure of enhanced biological production area for fish. One of the potential areas of fisheries are in archipelagic waters (Nurdin et al., 2013). The concentration of chlorophyll (presence of phytoplankton) in some area leads the aquatic life especially fish to live there because of food source (phytoplankton). Hence, it also can contribute to the fish population in the area. Oceanographic parameters will affect the presence of fish and the establishment of potential fishing areas (Ihsan et al., 2018). Thus, chlorophyll become as one of the selected parameters in determining the potential area for fish habitat. Table 3 shows the level of criteria and ranking for chlorophyll concentration. It showed that the mean value for chlorophyll concentration for fish distribution in range of $0.8-3.4 \mu \mathrm{g}$ liter-1. 
Table 3. Criteria and Ranking for Chlorophyll Concentration (Source: EPA, 2001)

\begin{tabular}{|c|c|c|}
\hline $\begin{array}{c}\text { Chlorophyll } \\
\text { Concentration }(\boldsymbol{\mu g} \text { liter-1) }\end{array}$ & Level & Ranking \\
\hline$<0.8$ & Low Range & 3 \\
\hline $0.8-3.4$ & Mean Range & 1 \\
\hline $3.4-7.6$ & Peak Range & 2 \\
\hline
\end{tabular}

For chlorophyll concentration, mean range $(0.8$ - $3.4 \mu \mathrm{g}$ liter-1) indicates the suitable range value for fish ground breeding area. Low chlorophyll concentration unable to make sure the fish grows healthily because it plays role as fish food. However, if the chlorophyll concentration is too high, it can affect the fish distribution. This is because algae blooms are not good for fish. Thus, it is important to make sure the chlorophyll concentration in mean range.

\subsection{Water Acidity}

Water acidity can be known as $\mathrm{pH}$ value of water. The term of $\mathrm{pH}$ describes how acidic or basic a substance is. The $\mathrm{H}$ refers to the number of hydrogen ions and hydroxide ions present in the liquid. The lower number of hydrogen ions present, the more acidic the substance. The higher number of hydrogen ions, the more basic the substance. The $\mathrm{pH}$ scale is a diagram that provides a visual guide for the different levels of $\mathrm{pH}$. Pure water has a neutral $\mathrm{pH}$ which is seven. The lower the number on the $\mathrm{pH}$ scale, the higher the amount of acid the substance has. Levels higher than 7 are more basic or alkaline.

Fish and other aquatic animal and plant life require the water they live in to be a certain $\mathrm{pH}$ level in order to be healthy. If the $\mathrm{pH}$ level is too low or too high, it can make fish sick even kill them. A low $\mathrm{pH}$ means that the water is acidic meanwhile high $\mathrm{pH}$ means that the water is alkaline. Different species require different $\mathrm{pH}$ levels. Some plants and aquatic animals can tolerate a higher acidity content or $\mathrm{pH}$ than others. Low $\mathrm{pH}$ is highly acidic and can burn a fish's skin. Young fish are more sensitive to higher acidic water than adult fish. Ocean water that has a $\mathrm{pH}$ of 5 is too acidic and will kill off the fish eggs and they will not hatch. It will reduce the fish's energy to take care of other tasks, such as digesting food, swimming rapidly to escape predators or catch food, and reproducing. It also able to slow down the fish's growth (Pistevos et al., 2017). Hence, the optimum range $\mathrm{pH}$ value is needed in order to make sure the fish can still survive. Table 4 displays the range of $\mathrm{pH}$ value for the fish. It showed that the optimum value for $\mathrm{pH}$ value for the fish survived is around 6.5 to 9.0 .

Table 4. Criteria and Ranking for Water Acidity (Source: Philminaq, 2015)

\begin{tabular}{|c|c|c|}
\hline $\mathbf{p H}$ & Effects on Fish & Ranking \\
\hline 4 to 5 & No Reproduction & 4 \\
\hline 4 to 6.5 & Slow Growth & 3 \\
\hline 6.5 to 9 & $\begin{array}{c}\text { Desirable Ranges for Fish } \\
\text { Reproduction }\end{array}$ & 1 \\
\hline 9 to 10 & Slow Growth & 2 \\
\hline
\end{tabular}

The best $\mathrm{pH}$ value for fish breeding area is 6.5 to 9.0 . Too acidic (water acidity) can affects fish growing and maturing. The ranking of criteria for water acidity can be seen in Table 4 .

\subsection{Dissolved Oxygen}

A few factors interact with each other in order to determine the amount of oxygen dissolved in surface waters. These factors are water temperature, water salinity, atmospheric diffusion, primary and secondary production and vertical stratification of the water column. Two main processes that increase the dissolved oxygen (DO) value are atmospheric diffusion and photosynthesis by primary producers. In order to survive, aerobic aquatic life need DO. Insufficient DO can cause mortality of fish and invertebrates, sub-lethal effects such as reduced growth and reproduction, and changes in behaviour, all of which can lead to an overall decrease in ecosystem productivity. The value of DO concentration declined with depth and hypoxia was more frequent at night and in the summer (Fong et al., 2003). A sufficient oxygen needed for normal mitochondrial function and energy production (ATP).

Thus, all aerobic, heterotrophic organisms such as bacteria, fish and invertebrates consume oxygen and generally comprise a significant portion of the biological oxygen demand biological oxygen demand (BOD) in an aquatic system. Table 5 shows the range value $(\mathrm{mg} / \mathrm{l})$ for dissolved oxygen. It can be concluded that value that higher than $2.3 \mathrm{mg} / \mathrm{l}$ contributes a better environment for fish population.

Table 5. Criteria and Ranking for Dissolved Oxygen (Source : EPA, 1986)

\begin{tabular}{|c|c|c|}
\hline Range & Description & Ranking \\
\hline$\geq 5.0 \mathrm{mg} / \mathrm{l}$ & Site meets protective criteria & 1 \\
\hline $\begin{array}{c}2.3 \mathrm{mg} / \mathrm{l}- \\
4 \mathrm{mg} / \mathrm{l}\end{array}$ & Site meets suitable range & 2 \\
\hline$<2.3 \mathrm{mg} / \mathrm{l}$ & $\begin{array}{c}\text { Site fails to meet objectives for } \\
\text { protection }\end{array}$ & 3 \\
\hline
\end{tabular}

Value of DO that higher than $2.3 \mathrm{mg} / \mathrm{L}$ contributes the best for fish distribution. When the site has DO value in range of $(2.3-$ $4.0 \mathrm{mg} / \mathrm{L}$ ), it meets the suitable range for the fish distribution and the site will meet protective criteria when the value of DO higher than $5.0 \mathrm{mg} / \mathrm{L}$. Low DO value can affect fish respiration. Ranking for best DO value for fish ground breeding shown in Table 5 .

\subsection{Water Salinity}

Among other factors, many studies have reported the influence of water salinity on fish development and growth. In most species, egg fertilization and incubation, larval growth are dependent on salinity. Fish growth also be controlled by salinity due to the presence of salts that dissolved in water (Riley et al., 1965). Chloride and sodium are the most important in normal salinity seawater.

Salinity influences the assembly of fish assemblages across completely estuarine systems. Somatic growth can be strongly affected by temperature and salinity (Ong \& Gan, 2017). Some species are known for their ability to acclimate to very different salinity media including an extreme environment. Table 6 illustrates the range of salinity value and their ranking for the fish. It can be said that the optimum value for water salinity in order to keep the fish alive is around 31 to $35 \mathrm{ppt}$. 
Table 6. Criteria and Ranking for Water Salinity (Source: Siddiquee et al., 2011)

\begin{tabular}{|c|c|c|}
\hline Water Salinity (ppt) & Range & Ranking \\
\hline $20-25$ & For diatom & 3 \\
\hline $26-30$ & Suitable range & 2 \\
\hline $31-35$ & Optimum range & 1 \\
\hline
\end{tabular}

Those criteria for the parameters has been defined by analysing from the previous research and the standard plus supported by localized data that has higher of fish numbers at once.

\section{MULTI-CRITERIA DECISION ANALYSIS}

Multi-criteria Decision Analysis (MCDA) is a method that can be applied to many complex decisions. Better decision can be made by the people or organizations when involving many choices. MCDA is concerned with structuring and solving decision and planning problems involving multiple criteria and support decision makers facing such problems. Choosing an appropriate decision making method, which fits the problem type, is the first step in the decision making process to achieve the goal and objectives.

Different types of problems and highlight their pros and cons must be compared in selecting the best method. Next, the requirements of a decision should be defined based on expert's judgments or any other technical restraints and the goals must be clarified. The next step is defining alternatives that, perfectly achieve the goals and decision-making is selected. It is involved defining and assessing the criteria. Then, selecting the decision method should be made. There are a few methods of MCDA which are Analytic Hierarchy Process (AHP), Preference Ranking Organization Method for Enrichment of Evaluations (PROMOTHEE), Fuzzy Logic Decision Making (FLDM) and Elimination and Choice Expressing Reality (ELECTRE).

For this study, AHP has been chosen as method in making decision for the criteria of parameters. AHP can provide decision makers with a robust solution. The most important part of this method is that; this method puts decision maker's preference in the first place and helps to select a method for their decision making in maintenance management without considering for making uncertainty rate and problem complexity.

\subsection{Analytical Hierarchy Process (AHP)}

Analytical Hierarchy Process (AHP) originally a mathematical tool is used to develop an instrument to upgrade the status of qualified higher education institutions (Sabaei et al., 2015). AHP method is a pairwise comparison in small part of hierarchical structure and then between higher levels of hierarchical structure. A theory of measurement through pairwise comparisons and relies on the judgments of experts to derive priority scale. These scale measure intangibles in relative terms (Saaty, 2008).

The AHP approach is a consensus, inclusive base decision without disregarding any opposing views. It simplifies a complex multi-decision making process, makes it more systematic, and introduces transparency while saving cost and resources. Within the framework, three layers of components with different criteria and indicators were built on top of each other. The criteria and indicators are changeable. The instrument is generic, flexible and applicable to any institution.
It allows users to take into account all-important criteria and to organize them into hierarchy. Major characteristic is the use of pair-wise comparisons, which are used to compare the alternatives with respect to the various criteria and to estimate weights (Velasquez \& Hester, 2013).

In order to work with AHP, it required a process that model the problem as a hierarchy. The purpose of modelling the problem as hierarchy is to present the problem at levels from general to detail in multileveled that AHP requires. A hierarchy is a stratified system of ranking and organizing people, things, ideas and more, where each element of the system, except for the top one, is subordinate to one or more other elements.

Generally, AHP method is used in evaluation of rural water supply system, desalination plants and building resilience to water scarcity. For instance, in evaluation of rural water supply, AHP is used to establish a composite sustainable management index for assessing long-term sustainability in the context of the level of service and evaluating the current performance level of piped-water supply schemes for establishing the weight of factors and sub-factors. AHP was used to determine the weights of the factors or parameters. This was based on scores of relative importance for each factor or parameter in pair-wise comparisons.

\subsection{Pair-Wise Comparison}

There are five parameters involved in this study which is water temperature, chlorophyll concentration, water acidity, dissolved oxygen and water salinity. These parameters are believed to be the most significance in contributing an optimum environment for the aquatic life according to their criteria (Portner \& Peck 2010). Comparison are made by pairing and comparing two indicators according to relative preferences of 1-9, as shown in Figure 3 . The value 9 indicates the most important meanwhile $1 / 9$ indicates the least important. When the number of parameters is $n$, a total of $n(n-1) / 2$ comparisons is made.

\begin{tabular}{|c|c|c|c|c|c|c|c|c|}
\hline \multirow[t]{2}{*}{ Extremely } & \multicolumn{3}{|c|}{ Less important } & \multicolumn{2}{|c|}{ Equally important } & \multicolumn{3}{|c|}{ More important } \\
\hline & $\begin{array}{l}\text { Very } \\
\text { strongly }\end{array}$ & Strongly & Moderately & $\begin{array}{l}\text { Equally } \\
\text { important }\end{array}$ & Moderately & Strongly & $\begin{array}{l}\text { Very } \\
\text { strongly }\end{array}$ & Extreme \\
\hline 1/9 & $1 / 7$ & $1 / 5$ & $1 / 3$ & 1 & 3 & 5 & 7 & 9 \\
\hline
\end{tabular}

Figure 3. Scale for weight assignment and its interpretation (Source : Saaty, 1980).

Figure 3 shows the comparisons ratings are on a scale of 1-9. Two parameters were considered at a time with each factor being scored according to its relative influence on an optimum environment for fishing site area. Figure 4 shows 2 parameters which are Water Temperature and Water Salinity have been compared respect to one of the factors or indicator which is fish health. It is best to compare the parameters by an expertise. These results in a ratio of importance for each pair with the maximum difference that one factor is nine times more important than other. Each parameter was compared to each other respect to their indicator, the parameters were assigned a value based on the relative important scale as shown in Figure 4 in order to determine a matrix of pair-wise comparisons of the criteria for the AHP process. This pair-wise comparison has been done by using Expert Choice software. 


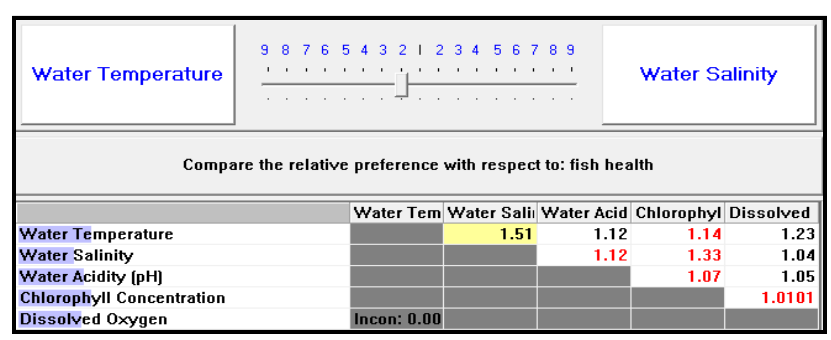

Figure 4. Example of pair-wise comparison between parameters.

The comparison began by comparing the first parameter in the row versus all of the parameters in the column. For instance, if Water Temperature is more important than Water Salinity then drag the point towards Water Temperature. The grey section in the pair wise comparison table contains formulas that automatically calculate the reciprocal of the values entered in the white section. The consistency ratio $(\mathrm{CR})$ value of pair-wise comparison measures the consistency of pair-wise assessment. If the number of inconsistencies larger than $10 \%$, then the pairwise comparison must be re-evaluated. The pair-wise comparison in Figure 5 shows the inconsistency value is 0.08 which is less than $10 \%$. Hence, the pair-wise comparison no need to be re-evaluated.

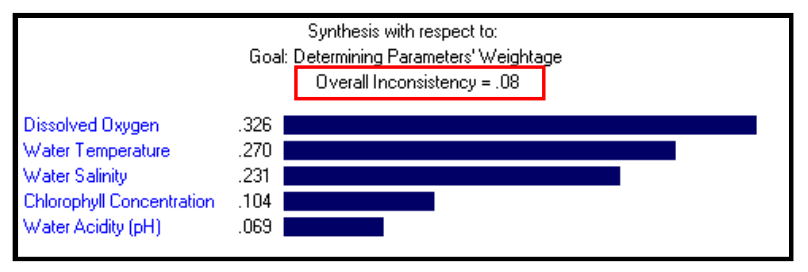

Figure 5. Inconsistency value for pair-wise comparison

After pair-wise comparison has been made, a value will be generated for each of the parameters that represented as their weightage. For instance, normalized weight for dissolved oxygen was 0.326 . Then, this weightage will be multiplied 100 to become as percentage and the output of pair-wise comparison reviewed in Table 7. These numbers were normalised to add up to become 100. The Dissolved Oxygen with the highest normalized weight represented as most important parameter followed by water temperature, water salinity, chlorophyll concentration and water acidity.

Table 7. Normalized Weight of the parameters

\begin{tabular}{|c|c|c|}
\hline Parameter & Normalized Weight (\%) & Ranking \\
\hline Dissolved Oxygen & 32.6 & 1 \\
\hline Water Temperature & 27.0 & 2 \\
\hline Water Salinity & 23.1 & 3 \\
\hline $\begin{array}{c}\text { Chlorophyll } \\
\text { Concentration }\end{array}$ & 10.4 & 4 \\
\hline Water Acidity (pH) & 6.9 & 5 \\
\hline
\end{tabular}

These parameters weightage will be used in overlay analysis to identify the potential fish ground breeding area. The importance level for the parameters were shown on ranking column. The first ranking indicates the most importance parameters followed by other parameters.

\subsection{Spatial Interpolation}

Interpolation tools that available in geographic information systems are useful and they allow the operator to easily perform different types of elaborations and display them graphically to display the results. In simple word, interpolation method helps in estimating unknown value from the known point or value which is using a linear combination of known functions with different weighting and neighbouring search schemes. Data that are closer to interpolation point have more influence (weight), during the computations, in comparison with faraway ones. There were numbers of methods for spatial interpolation that have been used and applied. The common spatial interpolation methods are Kriging Methods (Ordinary Kriging and Universal Kriging), Inverse Distance Weighting (IDW), Spline and Radial Basis Function (RBF). Ordinary kriging and universal kriging have been widely applied to environmental science, natural resources, remote sensing, and GIS.

For this study, Kriging Method in ArcGIS has been used to estimate the unknown value for the area. This method able to provide unbiased information for quantifies and able to generate estimate surface value from scattered points. Kriging method considers both distance and value of known points to other unknown points. This method has been chosen because it can help in estimating interpolation errors, has less Root Mean Square Error (RMSE) values, best for irregular data and effective on water quality parameters. RMSE indicates how close the model predicts with the measured values. The smaller this error, the better.

\subsubsection{Kriging Method}

Kriging method has been widely applied to the fields of geology, environmental science, geography and ecology. Kriging assumes that the distance or direction between sample points reflects a spatial correlation that can be used to explain variation in the surface. The Kriging tool fits a mathematical function to a specified number of points or all points within a specified radius, to determine the output value for each location. Kriging is an advanced geo-statistical procedure that generates an estimated surface from a scattered set of points with z-values. Unlike other interpolation methods in the Interpolation toolset, to use the Kriging tool effectively involves an interactive investigation of the spatial behaviour of the phenomenon represented by the z-values. Ordinary kriging and universal kriging are two common univariate kriging methods.

Ordinary kriging is the most general and widely used of the kriging methods and is the default. It assumes the constant means is unknown. Meanwhile, universal kriging assumes that there is an overriding trend in the data. This data can be modelled by a deterministic function, a polynomial. This polynomial is subtracted from the original measured points, and the autocorrelation is modelled from the random errors. Once the model is fit to the random errors and before making a prediction, the polynomial is added back to the predictions to give meaningful results. Universal kriging should only be used when the trend in the data is known. For this study, ordinary kriging method has been used to estimate the unknown value area.

\subsection{Parameters Reclassify}

Each parameter was reclassified after interpolation method is done. Reclassify is a geo-processing tool that reclassifies (or changes) the values in a raster. The results from interpolation were came out as raster. To represent a raster relative to these many different suitability weightings, the values on the raster must be changed from nominal values (values that represent a class) to interval or ratio values so that the values can be used in 
relation to one another. Then, these raster datasets have been used to reclassify the parameters according to their criteria.

Figure 6 shows the ranking value for Water Temperature. This ranking is divided according to their intensity colour. The higher intensity colour represents the best optimum area based on their criteria meanwhile the less intensity colour represents low optimum area. For Water Temperature, the optimum criteria are $28-30{ }^{\circ} \mathrm{C}$. As shown in the Figure 6, the best optimum area for water temperature conquered almost whole area boundary and in the middle area of the boundary. The unsuitable water temperature shown at near shoreline which is the water temperature at near the shoreline tends to have higher temperature due to low depth.

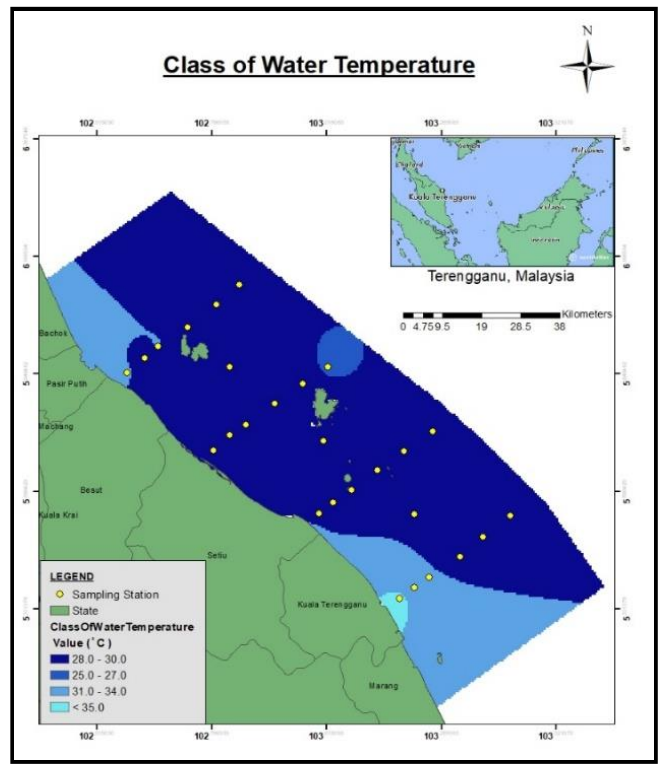

Figure 6. Class Value for Water Temperature

The quantity of chlorophyll concentration determine the availability of fish food. Higher chlorophyll concentration means higher food distribution in that area. Figure 7 shows the chlorophyll concentration in the area of study. It shows that, higher chlorophyll concentration located around 28 kilometres from the shoreline. The chlorophyll concentration increase when the area that has optimum water temperature. In this study area, lower range value of chlorophyll concentration became as domain.

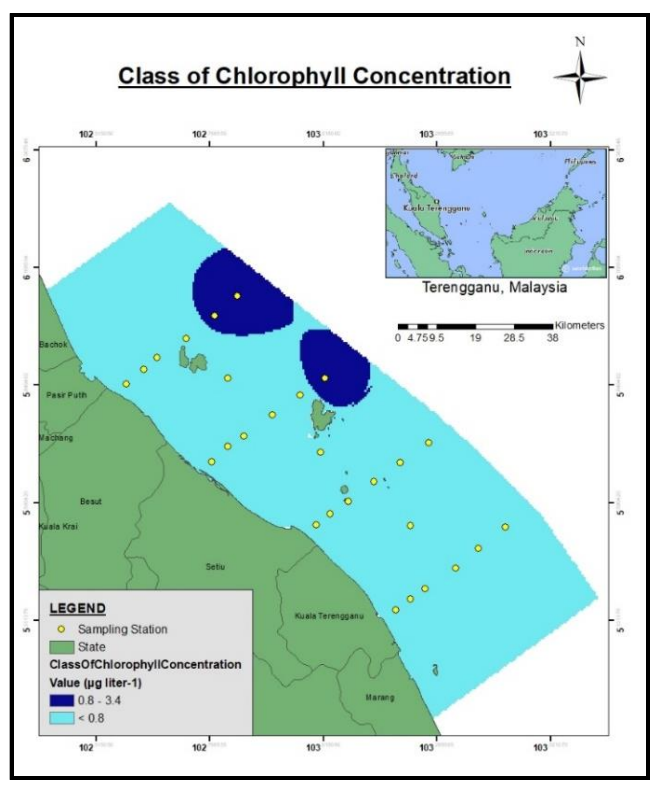

Figure 7. Class Value for Chlorophyll Concentration

Figure 8 shows the optimum area for water acidity. For this area, the value of water acidity is in range of 6.5 to 9.0 which is mean this area has optimum value for water acidity.

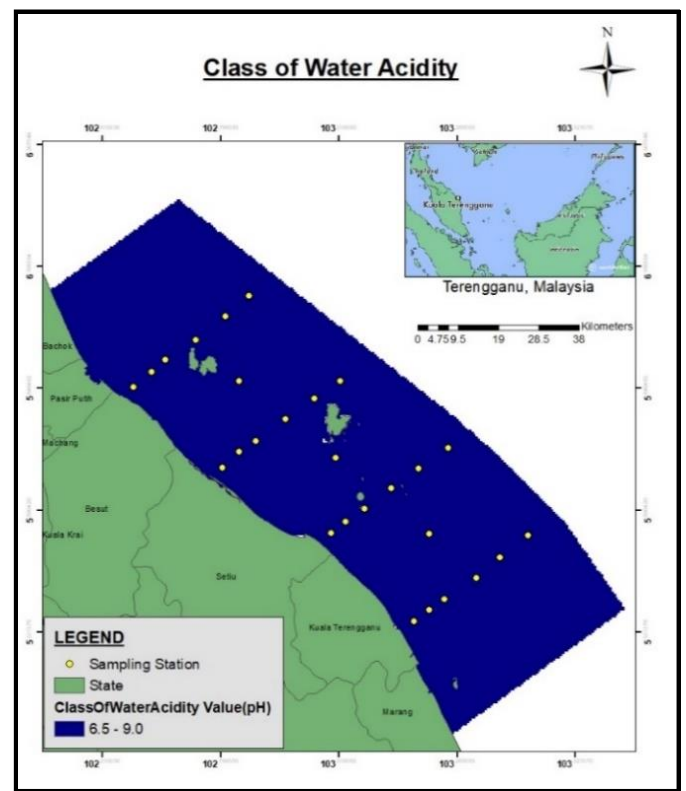

Figure 8. Class Value for Water Acidity

Higher concentrations of dissolved minerals, salt caused dissolved oxygen decrease. Figure 9 shows that, the study area is having optimum dissolved oxygen value. Dissolved oxygen is important for fish respiration. Higher dissolved oxygen generally found around the coral reefs due to photosynthesis and aeration from eddies and breaking waves. 


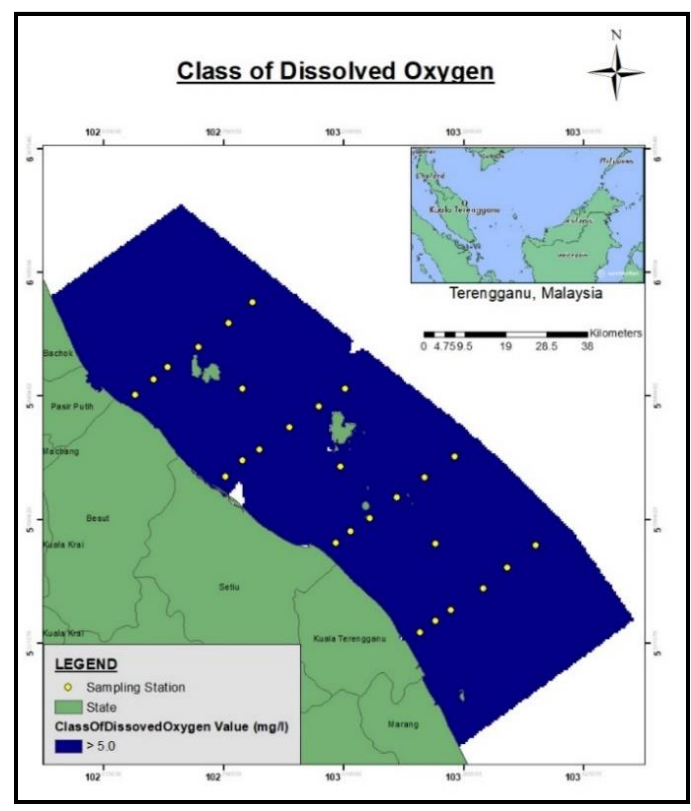

Figure 9. Class Value for Dissolved Oxygen

Water salinity is important in making sure the fish can growth healthily. The optimum water salinity is $28-31$ ppt. Figure 10 shows the higher intensity colour area that has optimum salinity value for the fish population.

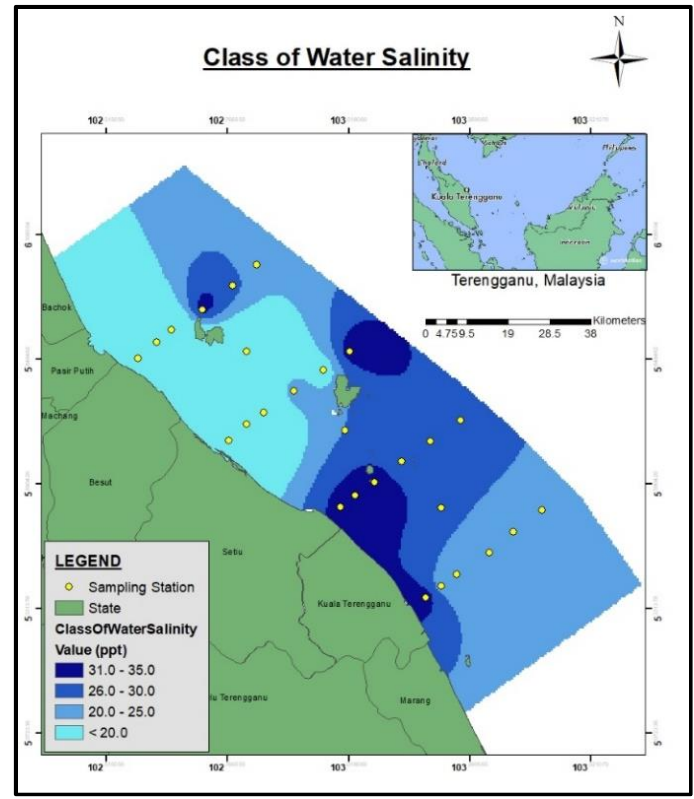

Figure 10. Class Value for Water Salinity

\subsection{Weighted Overlay}

Weighted overlay is an operation in Overlay toolset contained in Spatial Analyst Tools. Its function is to overlay several rasters using common measurement scale and weight each according to its importance. In this study, the weighted overlay will be used to overlay the parameters involved. Spatial analysis function is used to demonstrate the fish ground-breeding zone in the research area. In order to determine the fish ground breeding area, Weighted Overlay analysis was used to perform an overlay analysis for all the parameters. The Weighted Overlay tool under Spatial Analyst Tools in ArcGIS overlays several rasters using a common measurement scale weight each according to its importance. The result obtained from AHP which is parameters' weight will be used to generate the potential map. The spatial layers must be in raster data format. To overlay the spatial layers of parameters, the weighted overlay tool was being used as shown in Figure 11. All the parameters inserted in raster field and the value of weight for each parameter obtained from pair-wise comparison is inserted into the influence field. Influence of the raster must be as percentage as 100 compared to all parameters.

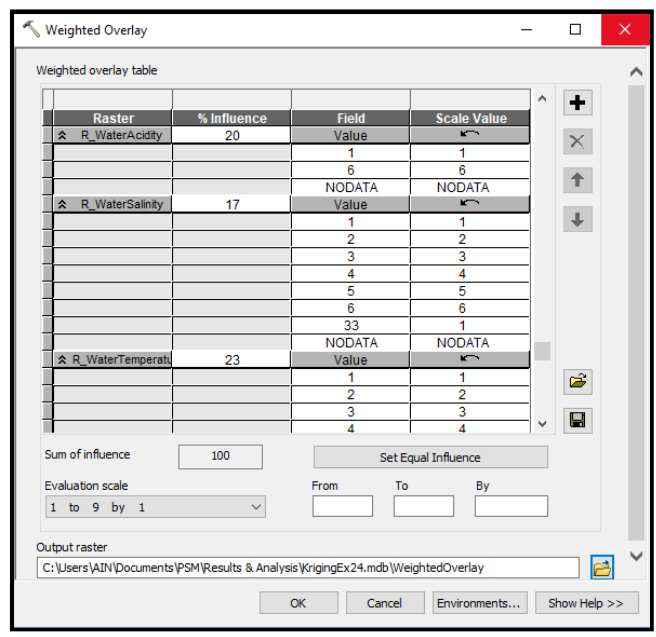

Figure 11. Weighted Overlay for Parameters

\section{RESULT AND DISCUSSION}

From the result of weightage overlay, the potential fish ground breeding area map is generated in Figure 12. The result was classified into four classes which are Very High, High, Moderate and Low. The highest intensity colour represent 'Very High' potential fish ground breeding area meanwhile 'High' potential fish ground breeding area represented by the higher intensity colour. For 'Moderate' potential fish ground breeding area is representing by low intensity colour and lowest intensity colour represents the area that has 'Low' potential fish ground breeding area.

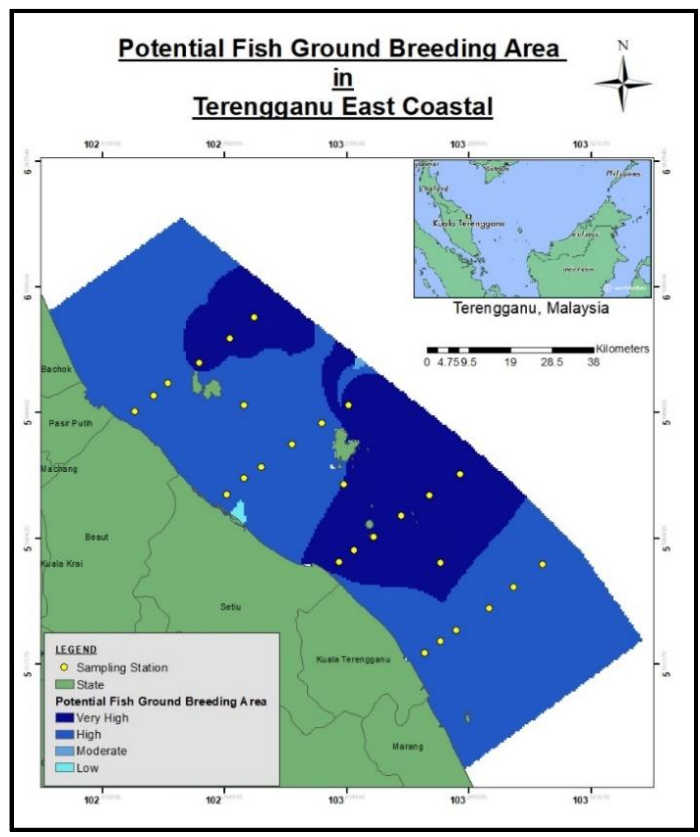

Figure 12. Potential Fish Ground Breeding Area 
Analysis for the potential fish ground breeding area shows that very high potential fish ground breeding area constituted $30.66 \%$ of the study area. High potential fish ground breeding area can be seen as major level in this study area by constituting about $69.04 \%$. A moderate potential fish ground breeding area occupies the area about $0.07 \%$ of the total study area meanwhile the area that fall under low potential fish ground breeding area constituting around $0.23 \%$ of the study area.

Map overlay between the predicted potential fish ground breeding and the parameters found that, the area that have very high potential fish ground breeding area consist optimum criteria for each parameter. Figure 12 shows the 'Very High' potential fishing site area covered around the high chlorophyll concentration which is mean the value of chlorophyll concentration affects the suitability or potential area for fish ground breading.

Moreover, this study area is categorized as epipelagic zone $(0-$ $200 \mathrm{~m}$ depth) which is known as the surface layer or photic zone where the light penetrates. This is the layer with the highest levels of dissolved oxygen due to wave action and photosynthesis (chlorophyll concentration). Area that has 'Low' potential fish ground breeding area can be seen around the shoreline which is shallow water compared other area. It is because the water temperature around the area caused the area become low suitable for fishing site area.

The map produced may facilitate the decision making process by identifying the potential fish ground breeding area. The area that labelled as very high potential for fish ground breeding area can be as information or marker for placing more artificial reefs in order to increase the fish population. This output able to make an accurate decision to place the artificial reefs without lose.

The accuracy of the GIS model of predicted potential fish ground breeding area map was validated with the existing artificial reefs which have high population of fish around it. These artificial reefs have been located and many fish populations spotted around it. The information of the parameters around the artificial reefs has been recorded to compare the parameters criteria in localize area (the existing artificial reefs location) by sampling with the standard of parameters' criteria that have been published. These data have been collected in July, 2018. Table 8 shows the data for water temperature and water salinity at existing artificial reefs area (localized area).

Table 8. Water Temperature and Water Salinity data at existing artificial reefs.

\begin{tabular}{|l|c|c|}
\hline \multicolumn{1}{|c|}{ Coordinates } & $\begin{array}{c}\text { Water } \\
\text { Temperature }\end{array}$ & Water Salinity \\
\hline $\begin{array}{l}\text { Lat : } 5.7408781 \\
\text { Long : } 103.0814719\end{array}$ & $24{ }^{\circ} \mathrm{C}-30{ }^{\circ} \mathrm{C}$ & $32 \mathrm{ppt}-34 \mathrm{ppt}$ \\
\hline $\begin{array}{l}\text { Lat : } 5.8157697 \\
\text { Long : } 103.0879906\end{array}$ & $24{ }^{\circ} \mathrm{C}-30^{\circ} \mathrm{C}$ & $32 \mathrm{ppt}-34 \mathrm{ppt}$ \\
\hline $\begin{array}{l}\text { Lat : } 5.81579 \\
\text { Long : } 103.0874854\end{array}$ & $25^{\circ} \mathrm{C}-30^{\circ} \mathrm{C}$ & $32 \mathrm{ppt}-34 \mathrm{ppt}$ \\
\hline
\end{tabular}

Table 8 shows the criteria for water temperature and water salinity at existing artificial reefs were in optimum range (see Table 2 and Table 6) for fish population. These data were similar to the parameters' criteria standard that has been used in this study Thus, the value of parameters criteria used in this study can be acceptable.

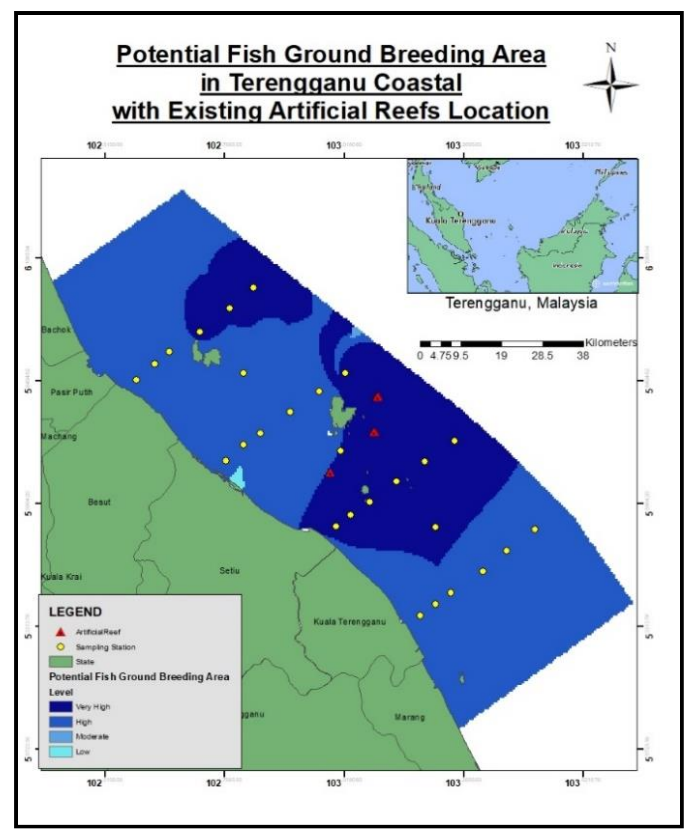

Figure 13. Potential Fish Ground Breeding Area with Existing Artificial Reefs Location

All existing artificial reefs seem located on the 'Very High' area in the map shown by Figure 13. Based on statistical data for 'Very High' fish ground breeding area, the area consists of optimum criteria for the parameters which are suitable for fish ground breeding area. This area potentially has many fish populations due to optimum criteria for the parameters around it. From the validation process, it can be concluded that the results for this study are acceptable and reasonable.

\section{CONCLUSION \& RECOMMENDATION}

In a nutshell, it is important to know the appropriate environment to serve as a new habitat for fish by analysing the parameters involved in that area. The criteria for the parameters need to be identified whether the ecosystem in a particular area is suitable for fish breeding or not. At the end of this study, the necessary criteria for the parameters involved in the particular area, which is more localized able to identify. Localized data have been applied in order to analyse and support localized criteria for this study area which is might be a suitable reef target area for the fish population. Those localize criteria able to help in identifying the potential fish ground breeding area by using multi-criteria decision analysis. Thus, this study able to help in locating the potential fish ground breeding area. This output of potential fish ground breeding area can be as information for placing the artificial reefs to sustainable the food security which is in fisheries sector by increasing the number of fish. By increasing the number of fish, it will help to decline at the rate of insufficient fish stock for economic growth. The result of this study can be assumed reasonable and acceptable because it has been validated by a strong point which is the location of artificial reefs that contain many numbers of fish. After the potential area that suitable for fish ground breeding has been located, the next artificial reefs can be placed correctly and the fishermen might able to know the area that tends to have many numbers of fish. 
Then, I would like to recommend the next research study for inserting the element of temporal to produce a better and good result in locating the potential area.

\section{ACKNOWLEGDEMENT}

I would like to express my special thanks of gratitude to my supervisor, Dr. Muhammad Imzan bin Hassan who helped me in doing my research study and I came to know about so many new things. Secondly, I would like to point out my grateful and many thanks to Dr. Razak bin Zakaria, lecturer of Universiti Malaysia Terengganu for sharing the data for my research study. Finally, I would also like to thank my parents and friends who helped me a lot in finalizing this project within the limited time frame.

\section{REFERENCES}

Barletta, M., A. Barletta- Bergan, U. Saint- Paul and G. Hubold (2005). "The role of salinity in structuring the fish assemblages in a tropical estuary." Journal of fish biology 66(1): 45-72.

Bohnsack, J. and D. L. Sutherland (1985). "Artificial Reef Research: A Review with Recommendations for Future Priorities." Bulletin of Marine Science 37: 11-39

Crawshaw, L. and J. Podrabsky (2011). "Behavioral Responses to The Environment Temperature Preference: Behavioral Responses to Temperature in Fishes."

EPA (1986). "Water Quality Standards for Coastal Waters Marine Outfalls." GSR 7.

EPA (2001). "Parameters of Water Quality Interpretation and Standards." Environmental Protection Agency, Ireland.

Fathi, S., A. Nahar Harun, S. Rambat and N. A. Tukiran (2018). "Current Issues in Aquaculture: Lessons from Malaysia."Advanced Science Letters 24: 503-505

Fong, P., K. Boyer, K. Kamer and K. A Boyle (2003). "Influence of initial tissue nutrient status of tropical marine algae on response to nitrogen and phosphorus additions." Marine Ecology Progress Series 262: 111-123

Heino, M. and O. R. A Godoe (2002). "Fisheries-Induced Selection Pressures in the Context of Sustainable Fisheries." IIASA Interim Report Bulletin of Marine Science 83, 1, p6993(25).

Ihsan, E. N., S. Y. Enita, Kunarso and A. Wirasatriya (2018). "Oceanographic Factors in Fishing Ground Location of Anchovy at Teluk Cenderawasih National Park, West Papua : Are These Factors Have an Effect of Whale Sharks Appearance Frequencies?" IOP Conference Series: Earth and Environmental Science 116: 012017.

Leeworthy, Maher \& Stone (2006) Leeworthy VR, Maher T, Stone EA. "Can artificial reefs alter user pressure on adjacent natural reefs? " Bulletin of Marine Science. 2006;78(1):29-37.
Nurdin, S., M. A. Mustapha and T. Lihan (2013). "The relationship between sea surface temperature and chlorophyll-a concentration in fisheries aggregation area in the archipelagic waters of spermonde using satellite images." AIP Conference Proceedings 1571(1): 466-472..

Ong, M. C. and S. L. Gan (2017). "Assessment of metallic trace elements in the muscles and fins of four landed elasmobranchs from Kuala Terengganu Waters, Malaysia." Marine Pollution Bulletin 124(2): 1001-1005.

Philminaq, (2015). "Water Quality Criteria and Standards for Freshwater and Marine Aquaculture". Marine Conservation Area.

Pistevos, J. C., Nagelkerken, I., Rossi, T., \& Connell, S. D. (2017). "Ocean acidification alters temperature and salinity preferences in larval fish." Oecologia, 183(2), 545-553. doi:10.1007/s00442-016-3778.

Portner, H. O. and M. A. Peck (2010). "Climate change effects on fishes and fisheries: towards a cause-and-effect understanding." J Fish Biol 77(8): 1745-1779.

Riley, G. A., D. Van Hemert and P. J. Wanngersky (1965). "Organic Aggregates in Surface and Deep Waters of the Sargasso Sea1." Limnology and Oceanography 10(3): 354-363.

Saaty, T.L., (1980). "The Analytic Hierarchy Process." McGraw-Hill, New York.Int. J. Services Sciences, Vol. 1, No. 1, 200883 Copyright (C) 2008 Inderscience Enterprises Ltd.

Saaty, T.L. (2008) "Decision making with the analytic hierarchy process." Int. J. Services Sciences, Vol. 1, No. 1, pp.83-98.

Sabaei, D., J. Erkoyuncu and R. Roy (2015). A Review of Multi-Criteria Decision Making Methods for Enhanced Maintenance Delivery." Procedia CIRP 37: 30-35.

Sheehy, D. and S. F. Vik (2010). "The role of constructed reefs in non-indigenous species introductions and range expansions." Ecological Engineering 36: 1-11

Siddiquee, S., N. Yusof, A. Salleh, G. Tan, F. Bakar, C. Yap, A. Ismail, S. Tan, L. Naher and C. Ho (2011). "Assessment of surface water quality in the Malaysian coastal waters by using multivariate analyses." Sains Malaysiana 40(10): 1053-1064.

Teal, L. R., J. J. de Leeuw, H. W. van der Veer and A. D. Rijnsdorp (2008). "Effects of climate change on growth of 0group sole and plaice." Marine Ecology Progress Series 358: 219-230.

Velasquez, M. and P. Hester (2013). "An analysis of multicriteria decision making methods." International Journal of Operations Research 10: 56-66

Revised August 2019 